\title{
Overview of Undergraduate Oncology Interest Groups: Medical Students' Insights from a National Collaborative Network
}

\author{
Kathrine S. Rallis ${ }^{1,2}$ (D) Yuxiao Alice Wang ${ }^{2}$ (D)
}

Accepted: 22 September 2020 / Published online: 24 September 2020

(C) American Association for Cancer Education 2020

To the Editor,

We read with interest the article by Malik et al. [1], "Mapping the Current State of Canadian Medical School Oncology Interest Groups," characterizing the activity level, resource availability, challenges, and employment perceptions reported by medical student leaders of Canadian Oncology Interest Groups (OIGs). As previous medical student lead of a London medical school OIG, and ambassador for the British Oncology Network for Undergraduate Societies (BONUS), this article resonates with us. We agree that OIGs offer tremendous potential to cultivate student interest in oncology alongside undergraduate medical curricula, though their full potential has yet to be recognized. In response to this, we offer insights from our experience with OIGs from our role in BONUS, highlight barriers in their function, and propose strategies to maximize benefits.

BONUS is a student-led collaborative network for undergraduate oncology societies across the United Kingdom (UK) that aims to increase collaborations between OIGs and promote oncology amongst students. In October 2019, we identified 21 OIGs each corresponding to one out of 42 recognized UK medical schools. Of these, 20 groups were active. The majority of OIGs were based at larger institutions, with smaller medical schools less likely to feature one. Anecdotally, UK OIGs comprise 5-15 student committee members, far more than the 2-3 reported in Canada [1]. Nevertheless, we report similar goals including increasing oncology exposure, enhancing education, promoting specialty selection, and establishing student-mentor relations. Events are also held, which include talks, conferences, networking meetings, and

Kathrine S. Rallis

k.s.rallis@smd16.qmul.ac.uk

1 Barts Cancer Institute, Queen Mary University of London, London, UK

2 Barts and The London School of Medicine and Dentistry, Queen Mary University of London, London, UK mentorships. Additionally, UK OIGs often "adopt" and support local cancer charities.

Although we face similar barriers including time restrictions, limited funding, and unsustainable student interest, we also encounter challenges recruiting mentors. Less than $25 \%$ of all contacted mentors agreed to participate in an organized mentorship program in 2019-2020, the results of which are due to be published. This was even more discouraging considering the high volume of student applications. Secondly, limited technology skills pose an obstacle in creating online platforms to advertise oncology-related opportunities including research projects, conferences, competitions, and electives [2]. Third, we agree that maintaining continuity is challenging; with committees reformed annually, connections are lost, and collaborations discontinued. Medical students who assume leadership roles are predominantly in senior years and face more time restrictions despite having more experience and connections, thus creating a vacancy upon graduation.

To address these issues, we strongly advocate for medical schools to provide infrastructure for online platforms, liaising with faculty oncologists to produce research, mentorship, and shadowing experiences. OIGs can assist in recruiting mentors and sourcing opportunities. Secondly, we propose the formation of a Canadian OIG network. From hosting events open to all students, to organizing conferences, UK OIGs have frequently succeeded in collaborations. Collaborations can sustain interest by increasing student numbers which may dwindle at single institutions. In addition, with the expanding role of telemedicine amid the coronavirus disease 2019 (COVID19) pandemic [3], further emphasis should be placed on creating online education and sharing resources. Virtual symposia are a promising strategy offering access to all $[4,5]$. Moreover, professional associations are key in supporting OIGs through funding or providing points of contact. Elective bursaries, academic prizes, and annual career days are effective at motivating students and cultivating specialty interest $[6,7]$. We urge oncologists to proactively seek out undergraduate OIGs to inspire a future generation of successors. 
As demand for oncologists increases [8] and curricula remain underrepresented $[9,10]$, OIGs offer invaluable access to an untapped source of future physicians. The potential of OIGs is enormous, though, being solely led by students, their full potential is unrealized. Medical schools, professional associations, and oncologists must join efforts to reinforce undergraduate OIGs to prevent specialty attrition, burnout, and decreased quality of service provisions.

Code Availability Not applicable.

Authors' Contributions KSR drafted the letter and reviewed the literature. YAW revised the final draft.

Data Availability Not applicable.

\section{Compliance with Ethical Standards}

Conflict of Interest The authors declare that they have no conflict of interest.

\section{References}

1. Malik NH, Li GJ, Giuliani M, Brundage M, Caissie A, Cao JQ, Halperin R, Ingledew PA, Vigneault E, Bezjak A (2020) Mapping the current state of Canadian medical school oncology interest groups. J Canc Educ. https://doi.org/10.1007/s13187-020-01803-4

2. O'Doherty D, Lougheed J, Hannigan A, Last J, Dromey M, O'Tuathaigh C, McGrath D (2019) Internet skills of medical faculty and students: is there a difference? BMC Medical Education 19:39. https://doi.org/10.1186/s12909-019-1475-4

3. Hollander JE, Carr BG (2020) Virtually perfect? Telemedicine for Covid-19. N Engl J Med 382:1679-1681. https://doi.org/10.1056/ NEJMp2003539

4. Price M (2020) Scientists discover upsides of virtual meetings. Science 368:457-458. https://doi.org/10.1126/science.368.6490. 457

5. McDowell L, Goode S, Sundaresan P (2020) Adapting to a global pandemic through live virtual delivery of a cancer collaborative trial group conference: the TROG 2020 experience. J Med Imaging Radiat Oncol 64:414-421. https://doi.org/10.1111/1754-9485. 13047

6. NANSIG and SBNS committees 2015-16 (2016) Rapid response: attracting students and junior doctors to apply for specialty training: lessons from the NANSIG-SBNS Neurosurgery Careers Day 2016. BMJ 351:h6945. https://doi.org/10.1136/bmj.h6945

7. Matyas ML, Ruedi EA, Engen K, Chang AL (2017) Life science professional societies expand undergraduate education efforts. CBE Life Sci Educ 16:ar5. https://doi.org/10.1187/cbe.16-01-0019

8. Erikson C, Salsberg E, Forte G, Bruinooge S, Goldstein M (2007) Future supply and demand for oncologists: challenges to assuring access to oncology services. J Oncol Pract 3:79-86. https://doi.org/ 10.1200/JOP.0723601

9. Payne S, Burke D, Mansi J, Jones A, Norton A, Joffe J, Cunningham D, McVie G, Agarwal R (2013) Discordance between cancer prevalence and training: a need for an increase in oncology education. Clin Med (Lond) 13:50-56. https://doi.org/10.7861/ clinmedicine.13-1-50

10. Mattes MD, Patel KR, Burt LM, Hirsch AE (2016) A nationwide medical student assessment of oncology education. J Cancer Educ 31:679-686. https://doi.org/10.1007/s13187-015-0872-6

Publisher's Note Springer Nature remains neutral with regard to jurisdictional claims in published maps and institutional affiliations. 